Usporedba metoda AA i Mehlich 3 za ekstrakciju kalcija i magnezija iz tala istočne Hrvatske

Comparison of AA and Mehlich 3 methods for calcium and magnesium extraction from eastern Croatia soils

Japundžić-Palenkić, B., Zebec, V., Romanjek Fajdetić, N., Blažinkov, M., Antunović, S., Rastija, D.

Poljoprivreda/Agriculture

ISSN: $1848-8080$ (Online)

ISSN: 1330-7142 (Print)

http://dx.doi.org/10.18047/poljo.25.1.6

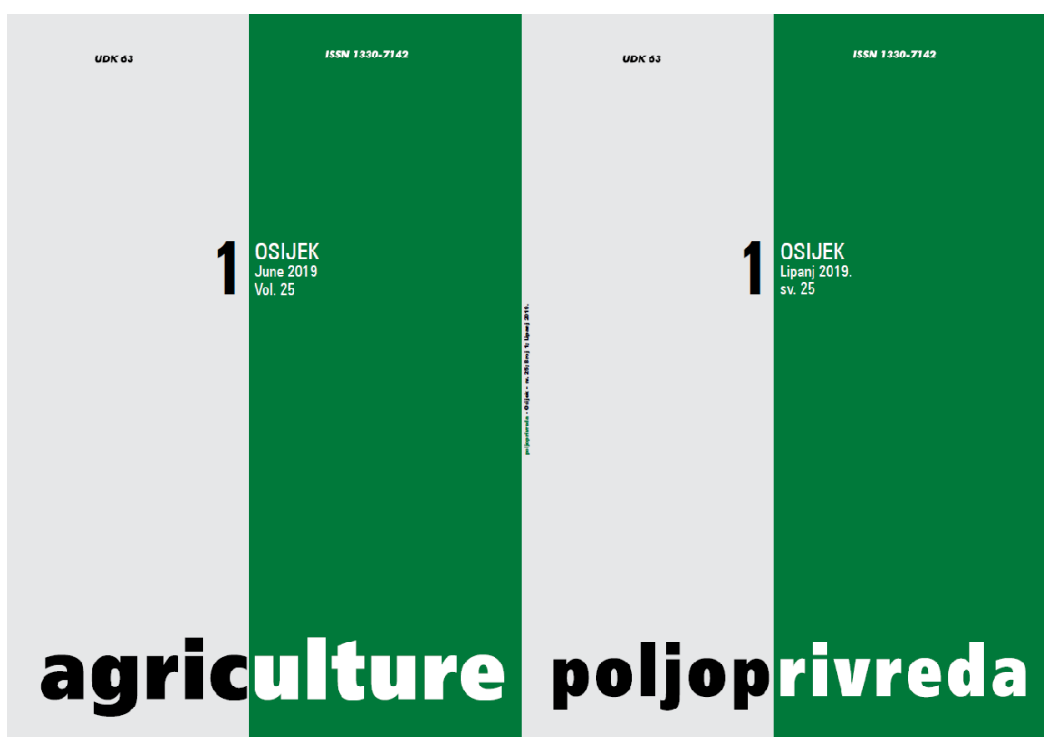

Fakultet agrobiotehničkih znanosti Osijek, Poljoprivredni institut Osijek

Faculty of Agrobiotechnical Sciences Osijek, Agricultural Institute Osijek 


\title{
USPOREDBA METODA AA I MEHLICH 3 ZA EKSTRAKCIJU KALCIJA I MAGNEZIJA IZ TALA ISTOČNE HRVATSKE
}

Japundžić-Palenkić, B. ${ }^{(1)}$, Zebec, V. ${ }^{(2)}$, Romanjek Fajdetić, N. ${ }^{(1)}$, Blažinkov, M. ${ }^{(1)}$, Antunović, S. ${ }^{(1)}$, Rastija, D. ${ }^{(2)}$

Izvorni znanstveni članak

Original scientific paper

\begin{abstract}
SAŽETAK
Kalcij i magnezij pripadaju skupini zemnoalkalijskih metala značajno zastupljenih u zemljinoj litosferi, odnosno skupini umjereno pokretnih makrohraniva koji imaju važnu ulogu u ishrani bilja. Svrha ovoga istraživanja jest usporedba količine ekstrahiranoga kalcija i magnezija otopinom amonijeva acetata (AA) i otopinom Mehlich 3 (Mehlich 3) iz tala istočne Hrvatske. Ukupno 200 uzoraka oraničnih horizonata 10 - $30 \mathrm{~cm}$ ) najzastupljenijih tipova tala prikupljeni su u pet županija istočne Hrvatske 2012. godine. Nakon određivanja pH vrijednosti i sadržaja ukupnih karbonata u tlu grupirani su uzorci tla (uzorci s manje od 3,5 i više od 3,5\% $\mathrm{CaCO}_{3}$ ). Utvrđeno je da metoda Mehlich 3 ekstrahira više kalcija i magnezija od metode AA, a razlike u količini ekstrahiranih kationa izraženije su kod karbonatnijih tala $\left(>3,5 \% \mathrm{CaCO}_{3}\right)$, posebno za kalcij. U tlima s manjim sadržajem $\mathrm{CaCO}_{3}$ utvrđena je statistički vrlo značajna korelaciju $(P \leq 0,01)$ između metoda $A A$ i Mehlich 3 u količini ekstrahiranoga kalcija i magnezija. Statistički je vrlo značajna korelacija $(P \leq 0,01)$ utvrđena i između količina Mg AA i Mg Mehlich 3 u tlima sa sadržajem $\mathrm{CaCO}_{3}$ većim od 3,5\%, što obje metode čini pogodnima za određivanje magnezija neovisno o sadržaju $\mathrm{CaCO}_{3}$ u tlu.
\end{abstract}

Ključne riječi: metoda AA, metoda Mehlich 3, kalcij, magnezij, $\mathrm{pH} \mathrm{CaCO}_{3}$

\section{UVOD}

Tla se razlikuju u pogledu fizikalnih i kemijskih svojstava koja utječu na količinu i vrstu izmjenjivih kationa, što predstavlja važan dio plodnosti tla. Biljke se koriste kationima kao hranivima, pa je očekivana povezanost utvrđenoga sadržaja kationa kemijskim ekstrakcijskim metodama i reakcije biljke. Međutim, interakcija između biljke i tla je vrlo komplicirana, pa veliki broj istraživača nastoji utvrditi oblik hraniva raspoloživ biljci koristeći se različitim ekstrakcijskim metodama (Ivezić i sur., 2013.), koje se razlikuju prema ekstrakcijskome sredstvu, duljini ekstrakcije, odnosu tla i ekstraktanta (Zebec i sur. 2017.a) te materijalnim troškovima. Općenito se smatra da su kiseli ekstraktanti prikladniji za kisela tla (Popović i sur., 2010.) jer metode s niskim pH vrijednostima ekstrakcijske otopine mogu generirati pogreške zbog otapanja soli iz karbonatnih tala (Wang i sur., 2005.). U tlima koja imaju prisutne slobodne karbonate ili druge soli postoji opasnost od otapanja i oslobađanja kationa u ekstrakcijsku otopinu te posljedično dobivanje pre- cijenjenih vrijednosti pojedinih kationa (Wolf i Beegle., 2009.; Warncke i Brown, 2012.). Neovisno o fizikalno-kemijskim svojstvima tla, u Hrvatskoj se za određivanje količine izmjenjivih kationa uobičajeno koristi metoda AA (Škorić, 1991.; Vukadinović i Lončarić, 1998.). Od svih metoda za određivanje izmjenjivih kationa ova je metoda zbog svojih prednosti (brzina metode, pristupačnost kemikalija, niska cijena, mogućnost istovremene analize velikoga broja uzoraka) najčešće korištena u svijetu (Aprile i Lorandi, 2012.). Na karbonatnim tlima koja sadrže $\mathrm{CaCO}_{3}$, metodom AA dobivaju se veće vrijednosti izmjenjivoga kalcija (Csathó i sur., 2000.; Wang i sur., 2005.) te je stoga prikladnija za kisela do slabo alkalna tla (Jones, 2001.). Mehlich 3 pripada metodama $\mathrm{s}$ vrlo kiselom ekstrakcijskom otopinom $(\mathrm{pH} 2,5)$ te se

(1) Dr. sc. Božica Japundžić-Palenkić, dr. sc. Nataša Romanjek Fajdetić, izv. prof. dr. sc. Mihaela Blažinkov, dr. sc. Slavica Antunović - Veleučilište u Slavonskom Brodu, Dr. Mile Budaka 1, 35000 Slavonski Brod, Hrvatska, (2) Doc. dr. sc. Vladimir Zebec (vzebec@fazos.hr), prof. dr. sc. Domagoj Rastija - Sveučilište Josipa Jurja Strossmayera u Osijeku, Fakultet agrobiotehničkih znanosti Osijek, V. Preloga 1, 31000 Osijek, Hrvatska 
uobičajeno koristi u Sjevernoj Americi (Jones, 2001.) i kao takva preporučena je za ekstrakciju kalcija u kiselim tlima (Warncke i Brown, 2012.). Prema Zebecu i sur. (2017.a,b), tla istočne Hrvatske na kojima je provedeno ovo istraživanje karakterizira varijabilni $\mathrm{pH}$ odnosno sadržaj karbonata. Cilj ovoga istraživanja bio je usporediti vrijednosti kalcija i magnezija dobivenih ekstrakcijom iz istih uzoraka tala istočne Hrvatske različitim analitičkim metodama (AA i Mehlich 3).

\section{MATERIJAL I METODE}

Uzorci najzastupljenijih tipova tala prikupljeni su u pet županija istočne Hrvatske 2012. godine. Brojem uzoraka proporcionalno su zastupljeni pojedini tipovi tala: lesivirano tlo, močvarno-glejno tlo (amfiglej, hipoglej), pseudoglej, pseudoglej-glej, eutrično smeđe tlo, ritska crnica, koluvij, aluvijalno tlo, rendzina, černozem, sirozem, distrično smeđe tlo i ranker. Ukupno je prikupljeno 200 uzoraka iz površinskih oraničnih horizonata tala (do dubine $30 \mathrm{~cm}$ ) koji su korišteni u intenzivnoj poljoprivrednoj proizvodnji, kao i „djevičanska tla”, odnosno tla pod prirodnom vegetacijom. Priprema uzoraka tla obavljena je prema protokolu HRN ISO 11464:2004 za kemijske analize tla. $\mathrm{Na}$ istraživanim uzorcima tala utvrđena je aktualna i supstitucijska kiselost elektrometrijski pH-metrom (ISO 10390, 2005.) Sadržaj karbonata u tlu određen je volumetrijskom metodom (HRN ISO 10693, 1995.) u uzorcima tala viših $\mathrm{pH}$ vrijednosti $\left(\mathrm{pH}_{\mathrm{KCl}}>5,5\right)$, nakon čega su uzorci podijeljeni na osnovi karbonatnosti prema studiji Soil Survey of England and Wales (Hodgson i Avery, 1976.). Za određivanje količine kalcija i magnezija $\mathrm{u}$ istraživanim uzorcima provedene su dvije različite komparativne ekstrakcijske metode: metoda s amonijevim acetatom (Jones, 2001.) i metoda Mehlich 3 (Jones, 2001.) (Tablica 1.). U svim ekstraktima izmjerena je koncentracija $\mathrm{Ca}$ i $\mathrm{Mg}$ emisijskom tehnikom na atomskom apsorpcijskom spektrofotometru Analyst 200 Perkin Elmer. Utvrđeni rezultati statistički su obrađeni računalnom aplikacijom Microsoft Excel uz primjenu Pearsonove metode za određivanje korelacijske povezanosti između ekstrahiranoga Ca i Mg metodama AA i Mehlich 3. Za provjeru statističke značajnosti koeficijenata korelacije korištena je Pearsonova tablica statističke značajnosti, koja pokazuje kritične vrijednosti (t) uz odgovarajuće stupnjeve slobode (SS ili df) na razini od 95 i $99 \%$.

Tablica 1. Usporedba ekstrakcijskih otopina, vremena ekstrakcije i odnosa tlo - ekstraktant.

Table 1. Comparison of extraction solution, time and soil - solution ratio for soil tests.

\begin{tabular}{|c|c|c|}
\hline $\begin{array}{l}\text { Metoda } \\
\text { Method }\end{array}$ & AA & Mehlich 3 \\
\hline $\begin{array}{l}\text { Ekstrakcijska otopina } \\
\text { Extraction solution }\end{array}$ & $1 \mathrm{M} \mathrm{NH}_{4} \mathrm{C}_{2} \mathrm{H}_{3} \mathrm{O}_{2}$ & $\begin{array}{c}0,2 \mathrm{M} \mathrm{CH} \mathrm{CH}_{3} \mathrm{COOH}+0,25 \mathrm{M} \mathrm{NH}_{4} \mathrm{NO}_{3}+0,015 \mathrm{M} \mathrm{NH}_{4} \mathrm{~F}+0,013 \mathrm{M} \mathrm{HNO}_{3} \\
+0,001 \mathrm{M} \mathrm{EDTA}\end{array}$ \\
\hline $\begin{array}{l}\text { pH otopine } \\
\text { Solution } \mathrm{pH}\end{array}$ & 7,0 & 2,5 \\
\hline $\begin{array}{l}\text { Odnos tlo - ekstraktant } \\
\text { Soil:extraction solution ratio }\end{array}$ & $1: 5$ & 1:10 \\
\hline $\begin{array}{l}\text { Vrijeme ekstrakcije } \\
\text { Extraction time }\end{array}$ & $5 \mathrm{~min}$ & $5 \mathrm{~min}$ \\
\hline
\end{tabular}

\section{REZULTATI I RASPRAVA}

Rezultati analiza 200 uzoraka tala korištenih za usporedbu analitičkih metoda bili su sljedeći: vrijednosti $\mathrm{pH}_{\mathrm{KCI}}$ bile su od 3,12 do 8,65, sadržaj karbonata od 0 do $34,8 \%$, kalcij ekstrahiran amonij-acetatom (AA Ca) od
45,83 do $4247 \mathrm{mg} \mathrm{Ca}^{2+} \mathrm{kg}^{-1}$, kalcij ekstrahiran metodom Mehlich 3 (Mehlich $3 \mathrm{Ca}$ ) od 39,70 do $16700 \mathrm{mg} \mathrm{Ca}^{2+}$ $\mathrm{kg}^{-1}$, količina magnezija ekstrahirana amonij-acetatom (AA Mg) bila je između 19,65 i $706 \mathrm{mg} \mathrm{Mg}^{2+} \mathrm{kg}^{-1}$, a metodom Mehlich 3 (Mehlich $3 \mathrm{Mg}$ ) od 26,40 do 2085 $\mathrm{mg} \mathrm{Mg}{ }^{2+} \mathrm{kg}^{-1}$ (Tablica 2.).

Tablica 2. Kemijska svojstva analiziranih uzoraka tala ( $\mathbf{n}=\mathbf{2 0 0}$, minimum, maksimum i prosjek).

Table 2. Chemical soil properties results ( $n=200$, minimum, maximum and average).

\begin{tabular}{|c|c|c|c|c|c|c|c|}
\hline \multirow{2}{*}{$\begin{array}{l}\text { Uzorci } \\
\text { Samples }\end{array}$} & \multirow{2}{*}{$\mathrm{pH}_{\mathrm{H} 20}$} & \multirow{2}{*}{$\mathrm{pH}_{\mathrm{KCl}}$} & $\mathrm{CaCO}_{3}$ & $\mathrm{AACa}^{2+}$ & Mehlich $3 \mathrm{Ca}^{2+}$ & $\mathrm{AA} \mathrm{Mg}^{2+}$ & Mehlich $3 \mathrm{Mg}^{2+}$ \\
\hline & & & $(\%)$ & \multicolumn{4}{|c|}{$\mathrm{mg} \mathrm{kg}^{-1}$} \\
\hline $\begin{array}{l}\text { Minimum } \\
\text { Minimum }\end{array}$ & 4,40 & 3,12 & 0,0 & 45,83 & 39,70 & 19,65 & 26,40 \\
\hline $\begin{array}{l}\text { Maksimum } \\
\text { Maximum }\end{array}$ & 8,92 & 8,65 & 34,8 & 4247 & 16700 & 706 & 2085 \\
\hline $\begin{array}{l}\text { Prosjek } \\
\text { Average }\end{array}$ & 7,01 & 5,84 & 3,1 & 1569 & 3803 & 179 & 533 \\
\hline
\end{tabular}


$\mathrm{Na}$ temelju utvrđenih $\mathrm{pH}$ vrijednosti $\left(\mathrm{pH}_{\mathrm{Kcl}}\right)$ uzorci tala bili su, prema Škorićevoj podjeli (1991.), od jako kisele do alkalične reakcije (Tablica 2.). Uvažavajući istu podjelu, grupi jako kiselih tala $(\mathrm{pH}<4,5)$ pripalo je 29 uzoraka, kiselim tlima (pH 4,5-5,5) 56 uzoraka, slabo kiselim tlima (pH 5,5-6,5) 38 uzoraka, dok je u grupi praktično neutralnih tala bilo 53 uzorka, a 24 tla svrstana su u grupu alkalnih tala $(\mathrm{pH}>7,2)$. Veći broj uzoraka u grupi kiselih tala (123 uzorka, od izrazito kiselih do slabo kiselih) očekivan je i u skladu s istraživanjima Mesića i sur. (2009.), koji navode da u Panonskoj regiji kisela tla zauzimaju 660.617 ha, što predstavlja $79,5 \%$ od ukupne površine kiselih tala u Hrvatskoj (831704 ha). Od ukupnoga broja analiziranih uzoraka (200 uzoraka), sadržaj karbonata $\left(\mathrm{CaCO}_{3}\right)$ utvrđen je u 114 uzoraka, dok je ostalih 86 uzoraka bilo beskarbonatno. Najveći broj uzoraka sadržavao je od 1 do $5 \% \mathrm{CaCO}_{3}$ (62 uzorka), u 18 uzoraka utvrđeno je više od $10 \% \mathrm{CaCO}_{3}$, od 5 do 10 $\% \mathrm{CaCO}_{3}$ imalo je 16 uzoraka, u 12 uzoraka utvrđeno je manje od $0,5 \% \mathrm{CaCO}_{3}$, a najmanji broj uzoraka (6) imao je od 0,5 do $1 \% \mathrm{CaCO}_{3}$. Budući da su analizirana tla bila od onih bez karbonata do vrlo karbonatnih tala, a zbog korištenja ekstraktivne otopine kisele reakcije koja je prilagođena za kisela tla (Popović i sur., 2010; Warncke i Brown., 2012.), bilo je očekivano da metoda Mehlich 3 korištena u ovom istraživanju otapa slobodne karbonate analiziranih tala. Uvođenjem podataka o karbonatnosti u korelacije između pojedinih metoda korištenih za ekstrakciju kationa utvrđeni sadržaj karbonata koji definira korelacijsku međuovisnost iznosio 3,5\% $\mathrm{CaCO}_{3}$ Ova vrijednost bila je osnova za usporedbu rezultata i utvrđivanje korelacije između istraživanih metoda. Tako je broj uzoraka svrstan u kategoriju tala $\mathrm{s}$ manjim sadržajem karbonata $\left(<3,5 \% \mathrm{CaCO}_{3}\right)$ iznosio 154 , dok je u kategoriju tala $\mathrm{s}$ većim sadržajem karbonata $\left(>3,5 \% \mathrm{CaCO}_{3}\right)$ svrstano 46 uzoraka. Metodom AA je prosječno ekstrahirano manje kalcija nego metodom Mehlich 3 (AA Ca $1569 \mathrm{mg} \mathrm{Ca}^{2+} \mathrm{kg}^{-1}$ prema Mehlich $3 \mathrm{Ca} 3803 \mathrm{mg} \mathrm{Ca}^{2+}$ $\mathrm{kg}^{-1}$ ), što je u skladu s istraživanjima Michaelsona i sur. (1987.). Također, razlika između minimalne i maksimalne količine kalcija ekstrahiranog metodom AA $(4201 \mathrm{mg}$ $\mathrm{Ca}^{2+} \mathrm{kg}^{-1}$ ) bila je nekoliko puta manja od razlike kalcija ekstrahiranog metodom Mehlich $3\left(16660 \mathrm{mg} \mathrm{Ca}^{2+} \mathrm{kg}^{-1}\right.$ ) (Tablica 2.).

Podjelom uzoraka prema sadržaju karbonata (Tablica 3.) dobivene su manje prosječne količine kalcija ekstrahiranog metodom AA (AA Ca $1300 \mathrm{mg} \mathrm{Ca}^{2+} \mathrm{kg}^{-1}$ odnosno $2469 \mathrm{mg} \mathrm{Ca}^{2+} \mathrm{kg}^{-1}$ ) prema kalciju ekstrahiranom metodom Mehlich 3 (Mehlich $3 \mathrm{Ca} 2294 \mathrm{mg} \mathrm{Ca}^{2+}$ $\mathrm{kg}^{-1}$ odnosno $\left.8855 \mathrm{mg} \mathrm{Ca}^{2+} \mathrm{kg}^{-1}\right)$.

Tablica 3. Količina ekstrahiranoga kalcija i magnezija (minimum, maksimum i prosjek) ovisno o sadržaju $\mathrm{CaCO}_{3}$. Table 3. Quantity of extracted calcium and magnesium (minimum, maximum and average) regarding $\mathrm{CaCO}_{3}$ content.

\begin{tabular}{|l|c|c|c|c|c|c|c|}
\hline \multirow{2}{*}{$\begin{array}{l}\text { Metoda } \\
\text { Method }\end{array}$} & \multirow{2}{*}{$\mathrm{CaCO}_{3}$} & \multicolumn{3}{|c|}{$\mathrm{Ca}^{2+}\left(\mathrm{mg} \mathrm{kg}^{-1}\right)$} & \multicolumn{3}{c|}{$\mathrm{Mg}^{2+}\left(\mathrm{mg} \mathrm{kg}^{-1}\right)$} \\
\cline { 3 - 8 } & & $\begin{array}{c}\text { Minimum } \\
\text { Minimum }\end{array}$ & $\begin{array}{c}\text { Maksimun } \\
\text { Maximum }\end{array}$ & $\begin{array}{c}\text { Prosjek } \\
\text { Average }\end{array}$ & $\begin{array}{c}\text { Minimum } \\
\text { Minimum }\end{array}$ & $\begin{array}{c}\text { Maksimun } \\
\text { Maximum }\end{array}$ & $\begin{array}{c}\text { Prosjek } \\
\text { Average }\end{array}$ \\
\hline \multirow{3}{*}{$\mathrm{AA}$} & $<3,5 \%$ & 45,83 & 4247 & 1300 & 19,65 & 596 & 194 \\
& $>3,5 \%$ & 1750 & 4090 & 2469 & 24,48 & 706 & 130 \\
\hline \multirow{3}{*}{ Mehlich 3 } & $>3,5 \%$ & 39,7 & 10560 & 2294 & 26,4 & 1635 & 543 \\
& $>3,5 \%$ & 4135 & 16700 & 8855 & 132 & 2085 & 497 \\
\hline
\end{tabular}

Metoda AA ekstrahirala je $56,64 \%$ kalcija od vrijednosti kalcija prema metodi Mehlich 3 u kategoriji tala $s$ manjim sadržajem karbonata (razlika je $995 \mathrm{mg} \mathrm{Ca}^{2+} \mathrm{kg}^{-1}$ ) i $27,88 \%$ u kategoriji tala s većim sadržajem karbonata (razlika je $6385 \mathrm{mg} \mathrm{Ca}^{2+} \mathrm{kg}^{-1}$ ). Kod metode AA utvrđen je porast vrijednosti ekstrahiranoga kalcija s porastom sadržaja $\mathrm{CaCO}_{3}$ u grupi tala s manje od 3,5\% $\mathrm{CaCO}_{3}$ (Grafikon 1.), što je u skladu s istraživanjima Csatha i sur. (2000.). Opadanje vrijednosti ekstrahiranoga kalcija s povećanjem sadržaja $\mathrm{CaCO}_{3}$ utvrđeno je u uzorcima s više od $3,5 \%$ $\mathrm{CaCO}_{3}$ (Grafikon 2.), što je vjerojatno posljedica zasi- ćenja ekstrakcijske otopine zbog otapanja karbonata (Dohrmann, 2006.). Neki autori navode da metoda AA ekstrahira veću količinu kalcija iz tala s većim sadržajem karbonata (Csathó i sur., 2000; Wang i sur., 2005.) s obzirom na to da $\mathrm{NH}_{4}{ }^{+}$iz AA otapa karbonate (Dohrmann, 2006.). Prema ovome istraživanju te količine nisu usporedive s metodom Mehlich 3, čiji ekstraktanti imaju nisku pH vrijednost i posljedično ekstrahiraju veće količine kalcija. Međutim, uočeno je da se porast količine ekstrahiranoga kalcija smanjuje i kod metode Mehlich 3 porastom sadržaja $\mathrm{CaCO}_{3} \mathrm{u}$ uzorcima tla (Grafikoni 1. i 2.). 


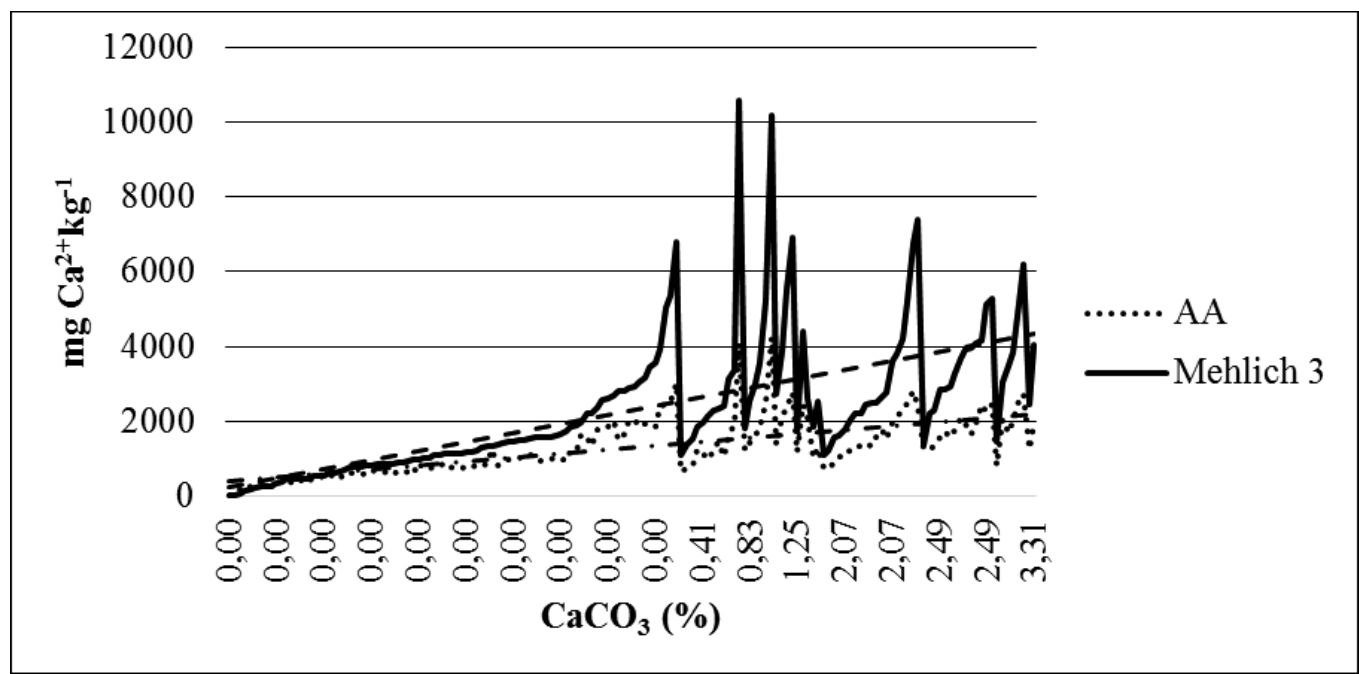

Grafikon 1. Ekstrahirani kalcij metodama AA i Mehlich 3 te linije trenda u uzorcima s manje od $3,5 \% \mathrm{CaCO}_{3}$. Graph 1. Extracted calcium by $\mathrm{AA}$ and Mehlich 3 methods and trend lines in samples with less than $3.5 \% \mathrm{CaCO}_{3}$.

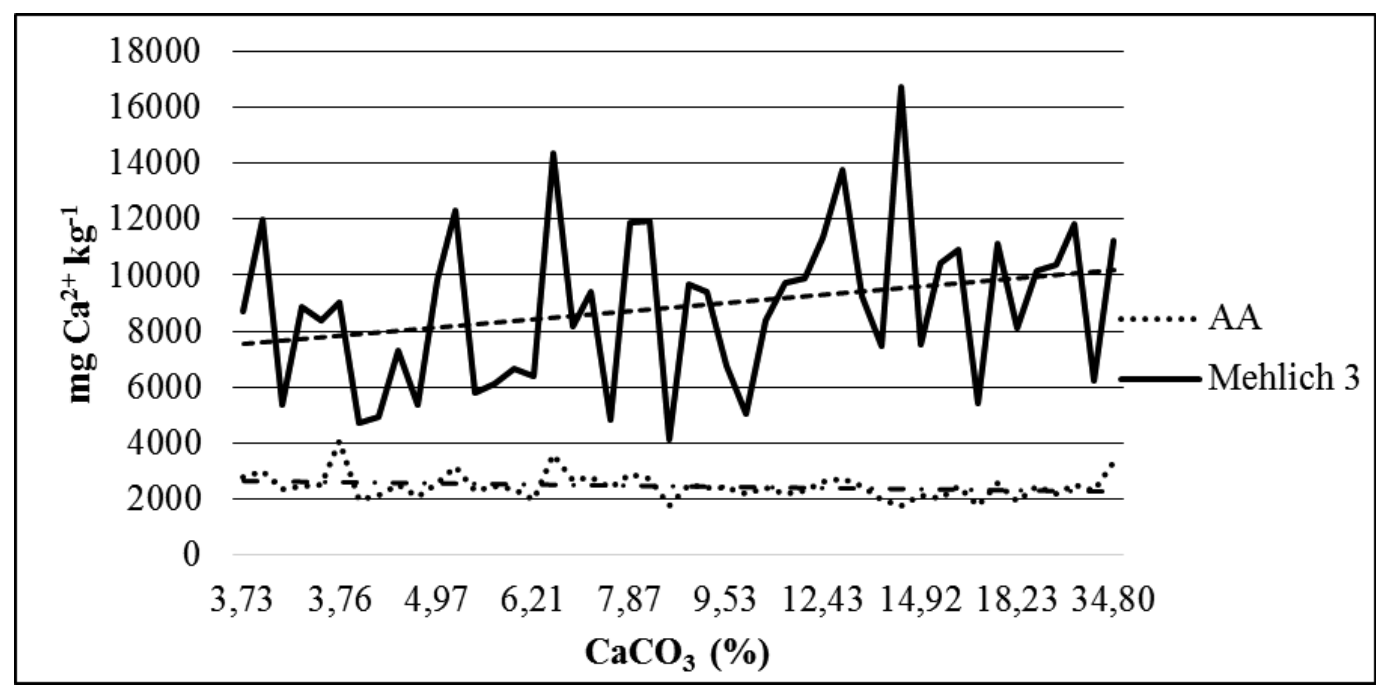

Grafikon 2. Kalcij ekstrahiran metodama AA i Mehlich 3 te linije trenda u uzorcima s više od $3,5 \% \mathrm{CaCO}_{3}$. Graph 2. Extracted calcium by $\mathrm{AA}$ and Mehlich 3 methods and trend lines in samples with more than $3.5 \% \mathrm{CaCO}_{3}$.

lako su postojale razlike u količini ekstrahiranoga kalcija (Tablica 4.), utvrđena je statistički vrlo značajna korelacija između metoda AA i Mehlich $3\left(r=0,85^{* *}\right.$, $\mathrm{n}=200$ ), što je u skladu s rezultatima prethodnih istraživanja (Chilimba i sur., 1999.; Wang i sur., 2004.; Mamo i sur., 2008.; Fukuda i sur., 2017.). Podjelom uzoraka prema količini $\mathrm{CaCO}_{3}$ (Tablica 4.) utvrđena je statistički vrlo značajna korelacija u tlima s manjim sadržajem karbonata $\left(r=0,96^{* *}, n=154\right)$ te statistički značajna korelacija $\left(\mathrm{r}=0,44^{*}, \mathrm{n}=46\right)$ u tlima s većim sadržajem $\mathrm{CaCO}_{3}$.

Tablica 4. Pearsonovi koeficijenti korelacije AA i Mehlich 3 za kalcij i magnezij.

Table 4. Pearson correlation coefficients $A A$ and Mehlich 3 calcium and magnesium.

\begin{tabular}{|l|c|c|c|c|}
\hline $\begin{array}{l}\text { Metoda } \\
\text { Method }\end{array}$ & & & $\begin{array}{c}\mathrm{AA} \\
\mathrm{Ca}^{2+}\end{array}$ & $\begin{array}{c}\mathrm{AA} \\
\mathrm{Mg}^{2+}\end{array}$ \\
\hline \multirow{4}{*}{ Mehlich 3 } & $\begin{array}{c}\text { Svi analizirani uzorci } \\
\text { All samples }\end{array}$ & $(\mathrm{n}=200)$ & $\mathrm{r}=0,85^{* *}$ & $\mathrm{r}=0,90^{* *}$ \\
\cline { 2 - 5 } & $<3,5 \% \mathrm{CaCO}_{3}$ & $(\mathrm{n}=154)$ & $\mathrm{r}=0,96^{* *}$ & $\mathrm{r}=0,88^{* *}$ \\
\cline { 2 - 5 } & $>3,5 \% \mathrm{CaCO}_{3}$ & $(\mathrm{n}=46)$ & $\mathrm{r}=0,44^{*}$ & $\mathrm{r}=0,97^{* *}$ \\
\hline
\end{tabular}

${ }^{*} \mathrm{P}<0,05$ statistički značajna korelacija, ${ }^{*} \mathrm{P}<0,01$ statistički vrlo značajna korelacija 
Manji koeficijent korelacije kod karbonatnijih uzoraka $\left(>3,5 \% \mathrm{CaCO}_{3}\right)$ u odnosu na sve uzorke i uzorke s manjim sadržajem karbonata $\left(<3,5 \% \mathrm{CaCO}_{3}\right)$ bio je očekivan jer je metoda Mehlich 3 ekstrahirala veću količinu kalcija od metode AA (Mehlich $3 \mathrm{Ca} 8855 \mathrm{mg} \mathrm{Ca}^{2+} \mathrm{kg}^{-1}$ prema AA Ca $2469 \mathrm{mg} \mathrm{Ca}^{2+} \mathrm{kg}^{-1}$ ) (Tablica 3.). U grupi tala s manjim sadržajem $\mathrm{CaCO}_{3}$ od $3,5 \%$ ta je razlika manja (Mehlich 3 Ca $2294 \mathrm{mg} \mathrm{Ca}^{2+} \mathrm{kg}^{-1}$ prema AA Ca $1300 \mathrm{mg} \mathrm{Ca}^{2+} \mathrm{kg}^{-1}$ ) (Tablica 3.), što potvrđuje činjenicu da je metoda Mehlich 3 pogodnija za kiselija tla (Warncke i Brown, 2012.). Osim kalcija, istraživanje je obuhvatilo i analizu magnezija te je iz uzoraka (Tablica 2.) ekstrahirana u prosjeku trostruko manja koncentracija magnezija metodom AA u odnosu na metodu Mehlich 3 (AA Mg 179 mg Mg${ }^{2+}$ $\mathrm{kg}^{-1}$ prema Mehlich $3 \mathrm{Mg} 533 \mathrm{mg} \mathrm{Mg}^{2+} \mathrm{kg}^{-1}$ ). Isto tako, razlika između minimalne i maksimalne vrijednosti $\mathrm{AA} \mathrm{Mg}$ bila je nekoliko puta manja od razlike utvrđene metodom Mehlich 3 (AA Mg 686,35 mg Mg${ }^{2+} \mathrm{kg}^{-1}$ prema Mehlich $3 \mathrm{Mg} 2058,60 \mathrm{mg} \mathrm{Mg}^{2+} \mathrm{kg}^{-1}$ ). Podjelom uzoraka prema sadržaju $\mathrm{CaCO}_{3}$ (Tablica 3.) dobivene su manje prosječne količine magnezija metodom $\mathrm{AA}$ u obje grupe tala ( $\mathrm{AA} \mathrm{Mg}$
$194 \mathrm{mg} \mathrm{Mg}^{2+} \mathrm{kg}^{-1}$ u tlima s $<3,5 \% \mathrm{CaCO}_{3}$ odnosno 130 $\mathrm{mg} \mathrm{Mg}{ }^{2+} \mathrm{kg}^{-1} \mathrm{u}$ karbonatnijim tlima) prema magneziju ekstrahiranom metodom Mehlich 3 (Mehlich $3 \mathrm{Mg} 543$ $\mathrm{mg} \mathrm{Mg}^{2+} \mathrm{kg}^{-1}$ odnosno $497 \mathrm{mg} \mathrm{Mg}^{2+} \mathrm{kg}^{-1}$ ). U kategoriji tala s manjim sadržajem $\mathrm{CaCO}_{3}$ metoda AA ekstrahirala je $36 \%$ magnezija od vrijednosti metode Mehlich 3 (razlika je $349 \mathrm{mg} \mathrm{Mg}{ }^{2+} \mathrm{kg}^{-1}$ ), a u kategoriji tala s većim sadržajem karbonata 26\% (razlika je $367 \mathrm{mg} \mathrm{Mg}^{2+} \mathrm{kg}^{-1}$ ). Slab porast količine ekstrahiranoga magnezija s porastom $\mathrm{CaCO}_{3}$ u analiziranim uzorcima utvrđen je kod metoda AA i Mehlich 3 (Grafikoni 3. i 4.). Niže vrijednosti AA Mg u karbonatnim tlima (Tablica 3.) dobili su i Csathó i sur. (2000.) u svojim istraživanjima. Statistički vrlo značajna korelacija $(\mathrm{P} \leq 0,01)$ u koncentraciji ekstrahiranog magnezija utvrđena je između metoda AA i Mehlich $3\left(r=0,90^{* *}\right.$, $\mathrm{n}=200$ ) (Tablica 4.). Vrlo sličnu vrijednost koeficijenta korelacije dobili su drugi istraživači (Chilimba i sur., 1999.; Wang i sur., 2004.). Također, u istraživanjima Mama i sur. (2008.), Staugaitisa i Rutkauskienè (2010.) te Fukude i sur. (2017.) vrijednosti AA Mg i Mehlich $3 \mathrm{Mg}$ bile su u značajnoj korelaciji.

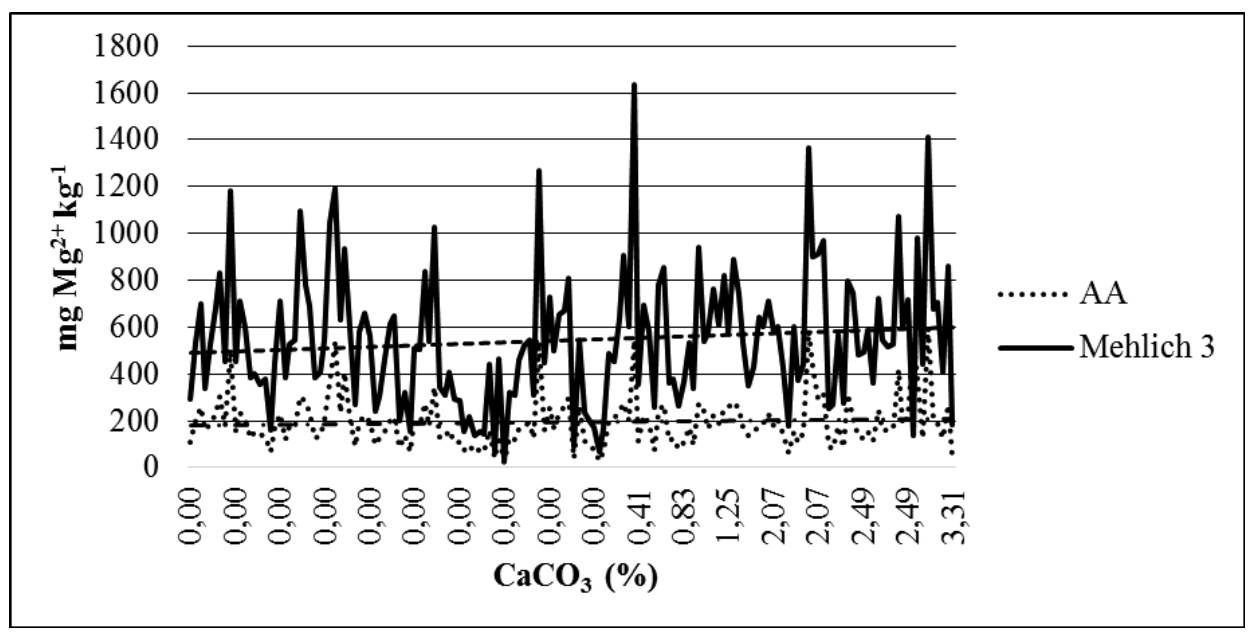

Grafikon 3. Magnezij ekstrahiran metodama AA i Mehlich 3 te linije trenda u uzorcima s manje od $\mathbf{3 , 5} \% \mathrm{CaCO}_{3}$. Graph 3. Extracted magnesium by $\mathrm{AA}$ and Mehlich 3 methods and trend lines in samples with less than $3.5 \% \mathrm{CaCO}_{3}$.

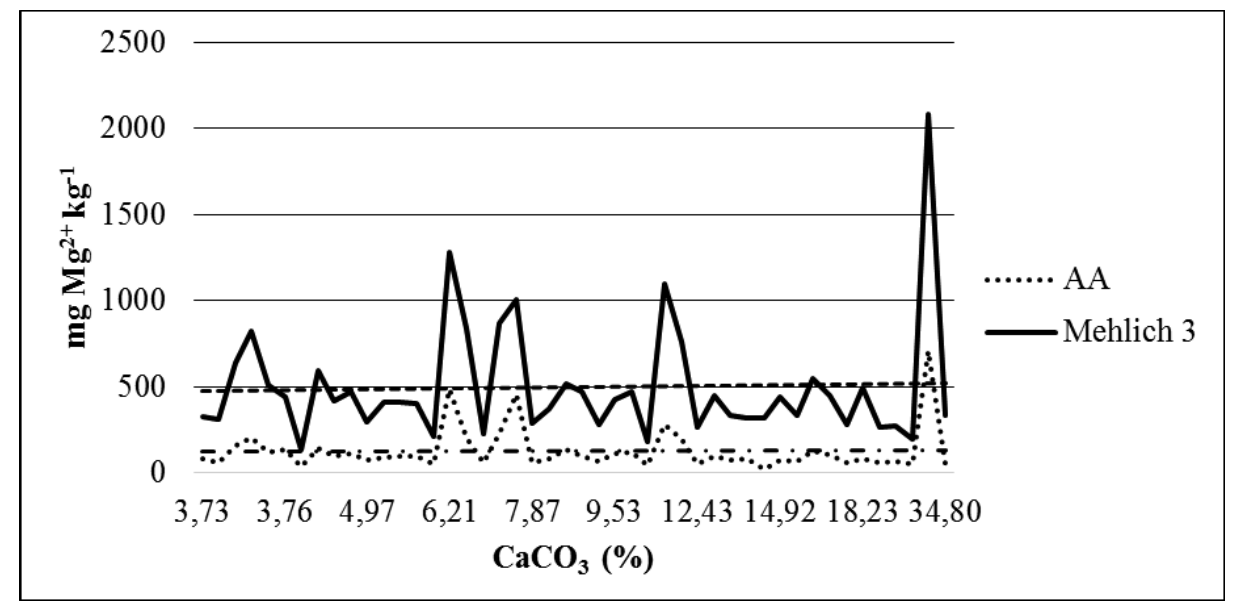

Grafikon 4. Magnezij ekstrahiran metodama AA i Mehlich 3 te linije trenda u uzorcima s više od $3,5 \% \mathrm{CaCO}_{3}$. Graph 4. Extracted magnesium by AA and Mehlich 3 methods and trend lines in samples with more than $3.5 \% \mathrm{CaCO}_{3}$. 
Podjelom uzoraka prema količini $\mathrm{CaCO}_{3}$ koeficijent korelacije se povećavao $\left(r=0,97^{* *}, n=46\right)$ u tlima $s$ većim sadržajem $\mathrm{CaCO}_{3}$ (Tablica 4.), dok se koeficijent korelacije u tlima s manjim sadržajem $\mathrm{CaCO}_{3}$ smanjio $\left(r=0,88^{* *}, n=154\right)$, ali je zadržana statistički vrlo značajna korelacija. Za razliku od kalcija, kod usporedbe ekstrakcijskih metoda AA i Mehlich 3 za analizu magnezija povećanje količine $\mathrm{CaCO}_{3} \mathrm{u}$ analiziranim uzorcima nije značajno utjecalo na razliku u količini ekstrahiranoga magnezija između metoda i unutar njih. S obzirom na to da karbonatna tla na lesu, kao matičnome supstratu, karakteriziraju područje smješteno na krajnjem istoku Republike Hrvatske (Drenjančević, 2012.), ovakvi rezultati mogu biti povezani s podrijetlom magnezijevih iona u tlu odnosno dominacijom kalcita nad dolomitima u sastavu tla, zbog čega je došlo do ekstrakcije samo „izmjenjivoga“ magnezija, a ne do ekstrakcije „izmjenjivoga i topivog" magnezija (Jones, 2001.).

\section{ZAKLJUČAK}

Metoda Mehlich 3 ekstrahirala je više kalcija i magnezija od metode $A A$, a razlike u količini ekstrahiranih kationa izraženije su kod karbonatnijih tala, posebno za kalcii $\left(>3,5 \% \mathrm{CaCO}_{3}\right)$. Rezultati ovoga istraživanja potvrđuju statistički vrlo značajnu korelaciju $(P \leq 0,01)$ između metoda AA (pH 7) i Mehlich 3 (pH 2,5) u količini ekstrahiranoga kalcija i magnezija u tlima istočne Hrvatske. Zbog izrazitijih razlika u količini ekstrahiranoga $\mathrm{Ca}$, metodama AA i Mehlich 3 utvrđen je manji korelacijski koeficijent kod karbonatnijih tala. Kod kalcija je utvrđeno povećanje koeficijenta korelacije u uzorcima tala s manjim sadržajem $\mathrm{CaCO}_{3}$, dok je porastom sadržaja karbonata smanjen koeficijent korelacije. Sadržaj $\mathrm{CaCO}_{3}$, odnosno pH vrijednost, nisu utjecali na koeficijent korelacije između Mg ekstrahiranoga metodama AA i Mehlich 3. Istraživanja treba nastaviti u pravcu detaljnije podjele uzoraka prema sadržaju karbonata ili $\mathrm{pH}$ vrijednosti kako bi se dobili precizniji rezultati korelacija između metoda AA i Mehlich 3 za utvrđivanje kalcija u tlu, dok su za određivanje magnezija u tlu pogodne obje metode neovisno o sadržaju $\mathrm{CaCO}_{3}$.

\section{LITERATURA}

1. Aprile, F., \& Lorandi, R. (2012): Evaluation of Cation Exchange Capacity in Tropical Soils Using Four Different Anlytical Methods. Journal of Agricultural Science, 4(6), 278-289.

2. Chilimba, A. D. C., Mughogho, S. K., \& Wendt, J. (1999). Mehlich 3 or modified Olsen for soil testing in Malawi. Communications in Soil Science and Plant Analysis, 30(7-8), 1231-1250.

3. Csathó, P., Debreczeni, K., \& Sárdi, K. (2000). K-Ca-Mg interactions in winter wheat in a network of Hungarian long-term field trials. Communications in Soil Science and Plant Analysis, 31(11-14), 2067-2079.

4. Dohrmann, R. (2006). Problems in CEC determination of calcareous clayey sediments using the ammonium acetate method. Journal of Plant Nutrition and Soil Science, 169, 330-334.
5. Drenjančević, M. (2012). Fe-kloroza vinove loze na podunavskoj podregiji. Poljoprivreda, 18(1), 65-75.

6. Fukuda, M., Nakamura, S., Fonesca, A. C. L., Nasukawa, H., Ibraimo, M. M., Naruo, K., Kobayashi, K., \& Oya, T. (2017). Evaluation of the Mehlich 3 reagent as extractant for cations and availabe phosphorus for soils in Mozambique. Communications in Soil Science and Plant Analysis, 48(12), 1462-1472.

7. Hodgson, J.M., \& Avery, B.W. (1976). Soil Survey field handbook: describing and sampling soil profiles. Soil Survey of Great Britain (England and Wales). Retrieved from https://www.sassa.org.uk/index.php/Analytical Methods:Field_Carbonate_Determination

8. HRN ISO 11464 (2004). Soil quality. Pretreatment of samples for physico-chemical analyses. Croatian Standards Institute (Zagreb).

9. ISO (1995). Soil quality. Determination of carbonate content. Volumetric method. HRN ISO 10693.

10. ISO (2005). Soil quality. Determination of $\mathrm{pH}$. International standard. ISO 10390.

11. Ivezić, V., Lončarić, Z., Engler, M., Kerovec, D., \& Singh, B. R. (2013). Comparison of different extraction methods representing available and total concentrations of $\mathrm{Cd}$, $\mathrm{Cu}, \mathrm{Fe}, \mathrm{Mn}$ and $\mathrm{Zn}$ in soil. Poljoprivreda, 19(1), 53-58.

12. Jones, J. B. (2001). Laboratory Guide for Conducting Soil Tests and Plant Analysis. CRC Press, Boca Raton, London, New York, Washington D.C.

13. Mamo, T., Richter, C., \& Heiligtag, B. (2008). Comparison of extractants for the determination of available phosphorus, potassium, calcium, magnesium and sodium in some Ethiopian and German soils. Communications in Soil Science and Plant Analysis, 27(9/10), 2197-2212.

14. Mesić, M., Husnjak, S., Bašić, F., Kisić, I., Gašpar, I. (2009). Excessive soil acidity as a negative factor for development of Croatian agriculture. Proceedings of the $44^{\text {th }}$ Croatian \& $4^{\text {th }}$ International Symposium on Agriculture, Opatija, Croatia: Faculty of Agriculture in Osijek, 16-20 February 2009, 9-18.

15. Michaelson, G. J., Ping, C. L., \& Mitchell, G. A. (1987). Correlation of Mehlich 3, Bray 1, and Ammonium Acetate extractable $\mathrm{P}, \mathrm{K}, \mathrm{Ca}$, and Mg for Alaska agricultural soils. Communications in Soil Science and Plant Analysis, 18(9), 1003-1015.

16. Popović, B., Šeput, M., Lončarić, Z., Andrišić, M., Rašić, D., Karalić, K. (2010). Comparison of AL P and Olsen P test in calcerous soils in Croatia. Poljoprivreda, 16(1), 40-57.

17. Škorić, A. (1991). Sastav i svojstva tla. Fakultet poljoprivrednih znanosti Sveučilišta u Zagrebu, Zagreb, Hrvatska.

18. Staugaitis, G., \& Rutkauskieneè, R. (2010). Comparison of magnesium determination methods as influenced by soil properties. Žemdirbystee (Agriculture), 97(3), 105-116.

19. Vukadinović, V., \& Lončarić, Z. (1998). Ishrana bilja. Osijek, Hrvatska: Poljoprivredni fakultet u Osijeku.

20. Wang, J. J., Harrell, D. L., Henderson, R. E., \& Bell, P. F. (2004). Comparison of soil-test extractants for phosphorus, potassium, calcium, magnesium, sodium, zinc, copper, manganese, and iron in Louisiana soils. Communications in Soil Science and Plant Analysis, 35(1-2), 145-160. 
21. Wang, O. R., Li, Y. C., Klassen, W. (2005). Determination of cation exchange capacity on low to highly calcareous soils. Communications in Soil Science and Plant Analysis, 36(11-12), 1479-1498.

22. Warncke, D., \& Brown, J. R. (2012). Potassium and other basic cations. In M. Nathan \& R. Gelderman (Eds.), Recommended Chemical Soil Test Procedures for the North Central Region (12 ed., pp. 7.1-7.3). Agricultural Experiment Stations of Illinois, Indiana, lowa, Kansas, Michigan, Minnesota, Missouri, Nebraska, North Dakota, Ohio, South Dakota and Wisconsin and the U.S. Department of Agriculture cooperating.

23. Wolf, A., \& Beegle D. (2009). Recommended soil tests for macro and micronutrients. In M. L. Horton (Ed.), Recommended soil testing procedures for Northeastern
United States (3 rd., pp. 39-48). Northeastern Regional Publication No. 493. Revised July 1, 2011. 10/2009. Retrieved from https://s3.amazonaws.com/udextension/ lawngarden/files/2012/10/CHAP5.pdf

24. Zebec, V., Rastija, D., Lončarić, Z., Bensa, A., Popović, B., \& Ivezić, V. (2017a). Comparison of Chemical Extraction Methods for Determination of Soil Potassium in Different Soil Types. Eurasian Soil Sc. 50: 1420-1427. https://doi.org/10.1134/S1064229317130051

25. Zebec, V., Semialjac, Z., Marković, M., Tadić, V., Radić, D., Rastija, D. (2017b). Influence of physical and chemical properties of different soil types on optimal soil moisture for tillage. Poljoprivreda, 23(2), 10-18. https://doi.org/10.18047/poljo.23.2.2

\section{COMPARISON OF AA AND \\ MEHLICH 3 METHODS FOR CALCIUM AND MAGNESIUM EXTRACTION FROM EASTERN CROATIA SOILS}

\section{SUMMARY}

Calcium and magnesium belong to a group of alkaline earth metals from lithosphere moderately mobile macronutrients which play an important role in plant nutrition. The aim of this paper was to compare quantities of extracted calcium and magnesium by ammonium acetate (AA) and by Mehlich 3 (Mehlich3) solutions from soils of eastern Croatia. The samples of the most representative soil types were gathered in five counties of eastern Croatia in 2012. After measuring the $\mathrm{pH}$ value and the overall carbonates being in soils, samples have been arranged into groups with less than $3.5 \%$ and more than $3.5 \% \mathrm{CaCO}_{3}$. It was determined that Mehlich 3 method extracts more calcium and magnesium than AA method and differences were especially pronounced for calcium in soils containing more carbonates. In soils with less $\mathrm{CaCO}_{3}$ the statistically very significant correlation (P $\leq 0.01)$ was determined between $A A$ and Mehlich 3 methods regarding extracted calcium and magnesium. The results of these studies confirmed significant correlation $(P \leq 0.01)$ between $M g A A$ and $M g$ Mehlich 3 methods in soils with more than 3.5\% $\mathrm{CaCO}_{3}$ making both methods suitable for $\mathrm{Mg}$ determination regardless the soil $\mathrm{CaCO}_{3}$.

Key words: AA method, Mehlich 3 method, calcium, magnesium, $\mathrm{pH}, \mathrm{CaCO}_{3}$

(Primljeno 16. listopada 2018.; prihvaćeno 27. ožujka 2019. - Received on October 16, 2018; accepted on March 27, 2019) 